\title{
SEISMIC BEHAVIOR AND STUDY OF RCS COMPOSITE FRAME COMPOSED OF STEEL BEAMS AND STRONG CONCRETE COLUMN
}

\author{
Ahmadreza KHODABANDEHLO ${ }^{1}$, Mohamad Taghi KAZEMI ${ }^{2, *}$ \\ ${ }^{1}$ Faculty of Civil Engineering Department, Central Qazvin Branch, Islamic Azad University, Qazvin, \\ Iran. \\ 2 Faculty of Civil Engineering Department, Sharif University, Tehran, Iran. \\ corresponding author: kazemi@sharif.edu.
}

\begin{abstract}
With spreading of population and increasing of instruction, and also because of limited resources and materials, the demand for using novel materials in building industry has increased. The reinforced concrete columns and steel beams are used in structures with composite moment frame (RCS). Use of compression strength in proportion with concrete and bending strength of steel beam has bestowed these structures less weight than that of concrete structures and made it easier to access the measure of strong column - weak beam especially within long span in these structures. The most important part of these structures is connection of steel beam with the reinforced concrete column. These connections are divided into two general groups of connection with bracing beam and with bracing column from the joint. This paper aims to study the seismic behavior and parameters of RCS composite frame composed of steel beams and strong concrete column. The finite element method was analyzed by ABAQUS software and data analyzed by Excel.
\end{abstract}

\section{Keywords:}

Bending Frame;

Composite;

Reinforced Concrete Column;

Steel Beam.

\section{Introduction}

With spreading of population and increasing of instruction and also because of limit resources and materials, demand for novel materials in building industry has increased. New technologies offered different methods of construction to engineers. Correct analysis of novel created technologies in structures on one hand, and familiarity with new material on the other hand, helped engineers and architects to find new methods of construction and try for new solutions of quality correction and increase of efficiency of the new materials in this industry.

Since it is impossible to prevent from earthquake, making safety of buildings against the natural phenomenon is inevitable. On other hand, technology development in all fields including building, and also wide conducted studies and investigations about seismic behavior of buildings, has provided the possibility of use of the new systems in retrofitting the existing structures [1].

One of novel structure is the composite bending frame (RCS). Reinforced concrete column and steel beams are used in these structures. Use of compression strength in proportion with concrete and bending strength of steel beam in these structures bestowed them less weight compared to the concrete ones and made it easier to access the measure of strong column - weak beam especially within long span in these structures.

Control of energy and vibrations made by earthquake in both of concrete and steel structures is one of main issues of seismic retrofitting. In concrete structures, systems of energy dissipation, especially dampers, are used in most of shear walls. Because kind of the used damper can influence attenuation and energy dissipation due to earthquake, the used physical specifications are also determining in this field. So, this study aims to investigate the role of frictional damper in the concrete structure with high strength. Concrete compression strength maybe is the most important quality measure. Some factors such as aggregates specification from the aspect of form, texture and their 
maximum size, value of consumed concrete and ratio of water to concrete, affects the concrete compression strength. Concrete with compression strength more than $50 \mathrm{Mpa}$ are high- strength concrete (HSC). The kind of concrete is used more in heavy structures such as dam and atomic energy facilities [2]. So, this study aims to investigate the seismic behavior, and parameters of the RCS composite frames composed of steel beams and strong concrete columns.

\section{Concept of performance in evaluating and design of structures}

The first step in evaluating and seismic retrofit of structure is choosing a proper performance aim point according to the importance of the structure and economic conditions. After that the seismic demand and the maximum permitted damage for being used in the seismic evaluation and plan of reinforcement of buildings' structural and unstructural systems should be determined. For evaluation and seismic retrofit of structures the follow should be regarded:

- In severe earthquakes which may happen several times during the useful life of a structure, we should prevent from structural and unstructural damages to prevent from stop in utilizing building.

- In moderate earthquakes which may happen within the useful life of a building we should try to keep the structural damages at minimum to safe habitants.

- In sever earthquakes which happen rarely, we should prevent from complete collapse of a structure so if possible we can utilize it with seismic retrofit [3].

\section{Steel structures}

By steel structures in construction we mean framed structures. Role of the frame in a building is transferring of dead and dynamic loads, earthquake load and snow load from structure to foundation and preserving the total stability of a structure. Rolled profiles are used in most of building structures. If the designed dimensions have another values the needed profile can be prepared using sheets available in the market [4].

For decreasing of vibrations induced by wind or earthquake in tall buildings, a new device has been invented and used. Devices needed for decreasing vibrations of a structure have been divided into several groups. In recent years controlling a structure has been in the form of a practical technology for protection structures against wind load and earthquake. The method of resistance of a building against lateral loads based on input energy is categorized into three major groups of passive, semi-active and active control.

Passive control devices are those systems that don't need external energy source. These devices utilize forces created by response of structure. Base isolation and tuned mass damper are in this group.

In active control, the responses of a structure decrease by the external energy imposed on the structure. These systems are controllable plants which import controlling energy on buildings with an auxiliary tool. For example a cable connected to a building import force to the building against the shear forces imposed by earthquake. Active systems are more effective than passive ones, but have the disadvantage of high execution and maintaining costs. An example of such systems is active mass dampers.

Semi-active systems are controllable plants which compared to the active control systems need less energy. In these systems, energy isn't injected into the system, so stability will be preserved in all levels. For example there is variable orifice damper for creating variable stiffness [5]. In recent years so many efforts have been taken place for design and evaluation methods of buildings based on displacement (transformation) and direct use of nonlinear analyses for real evaluation of structures behavior. These efforts resulted in nonlinear static analysis called Pushover analysis which today as a useful device has found a wide range of use in the earthquake performance - based engineering and can offer useful information about nonlinear behavior of structures, region of formation of plastic joints and way of redistribution of forces, which aren't accessible by linear static analysis methods.

\section{Pushover modal analysis method}

In the Pushover modal method (MPA) the imported load by earthquake is analyzed in the form of modal loads and written as combination of modal loads. 
Modal loads are inertia forces corresponding with each mode so if a structure with multi degree of freedom got affected by each of these modal loads, just the related mode in the structure will be excited and all responses be in that mode. In fact a structure with multi degree of freedoms changes to a single degree of freedom structure [6].

Nonlinearity of a problem can be defined in two forms of geometric nonlinearity and material nonlinearity. The former is included of geometric changes of a structure. In the kinds of problems, the stiffness matrix of the structure is a function of displacement vector and its derivatives, and the latter one includes problems which may happen in the case of existence of a nonlinear relationship between tension and strain of materials (in these materials tension is a nonlinear function of strain). Concrete is a kind of such material. In the structures with reinforced concrete material, both of the concrete and steel have nonlinear behavior.

Reinforcement of concrete beam with some materials like steel bars has been in attention from many years ago. Steel bars increase bearing capacity of a beam. Experimental studies show that steel bars increase the bending and shear capacity of a beam. Although the experimental method is acceptable for investigation about behavior of the concrete reinforced beams, because of high costs of the experimental method and long-time researches we can predicate the behavior of reinforced concrete beams with numerical modeling in the finite limit software.

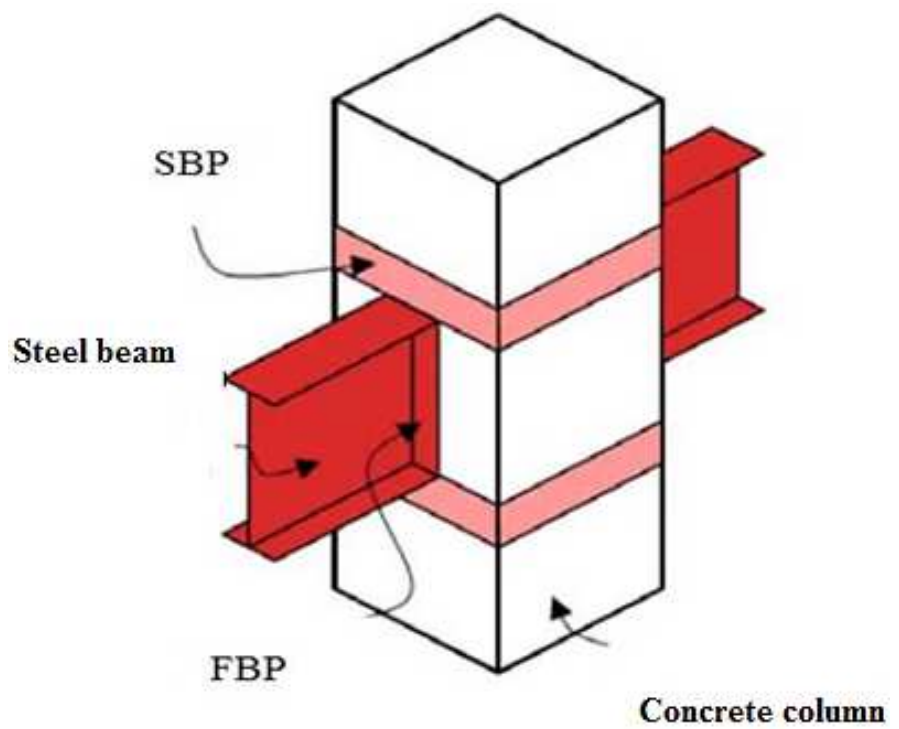

Fig. 1: Details of RCS standard connection.

General behavior of structures is divided into three categories:

1. Structures with low resistance and flexibility,

2. Structures with moderate resistance and high flexibility,

3. Structures with high resistance and low flexibility. Below figure show the general behavior of structures.

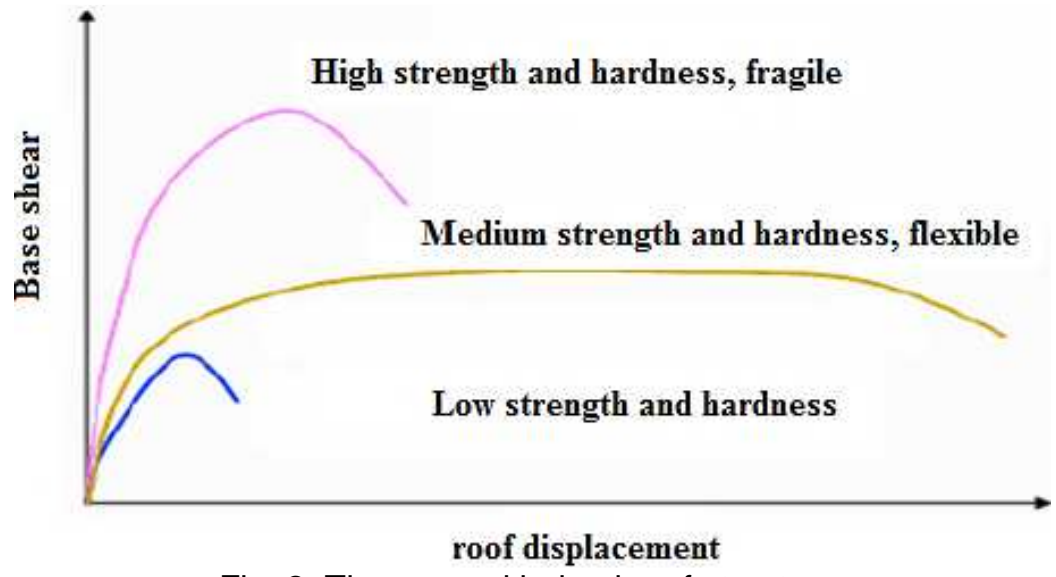

Fig. 2: The general behavior of structure. 
Bending frames bear the lateral loads by nodes rotation through creating moment and shear in frame members. Because of disturbing moments which are created by lateral forces, axial forces are created in the frame column. In buildings which have floor and roof diaphragm we the axial forces in the ledger can be ignored. Because the bending frames stand against the lateral loads through nodes rotation, displacements or lateral displacements of such frames against severe earthquake can be impressive [7].

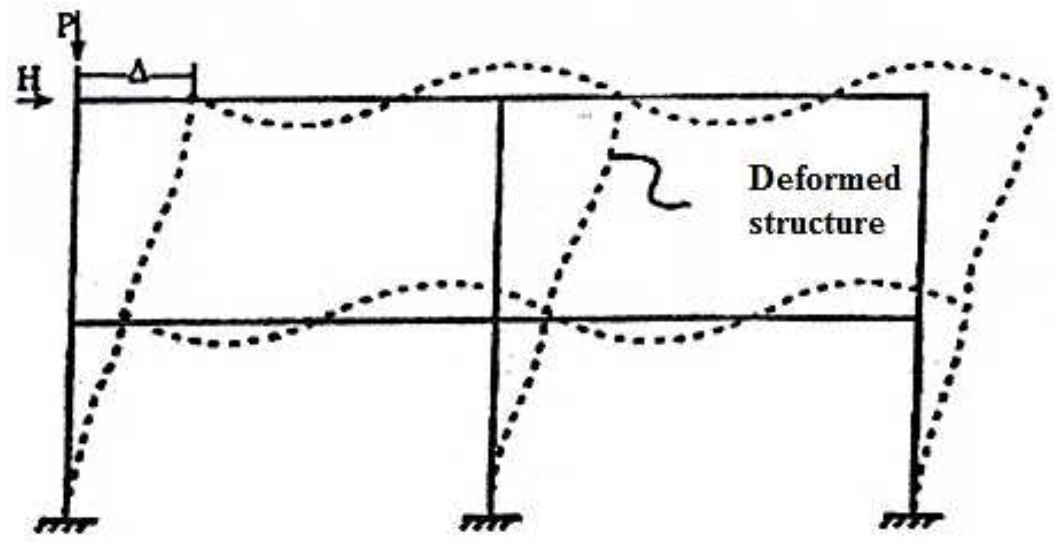

Fig. 3: Lateral deformation.

These two deformations are created because of two major factors:

1. Deformation induced by cantilever bending.

2. Deformation induced by bending of columns and beams.

The lateral deformation induced by cantilever bending, which also is called chord thrust, is created by short and lengthening of column length (axial deformation of column) (Fig. 4b). This state of deformation constitutes 20 percent of total lateral displacement of a structure.

Lateral deformation induced by bending of beams and columns is also called shear moment. In this phenomenon the horizontal and vertical shear forces are imposed on the columns and beams respectively and made bending moments in these members. Finally because of bending deformation of beams and columns all the frame is deformed (Fig. 4c). This state of deformation constitutes 80 percent of lateral deformation of the structure from which 65 percent is induced by bending of beams and 15 percent by that of columns [8].

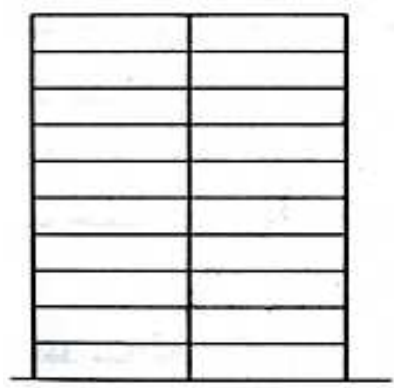

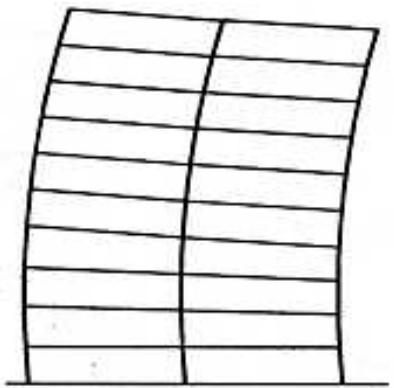

b

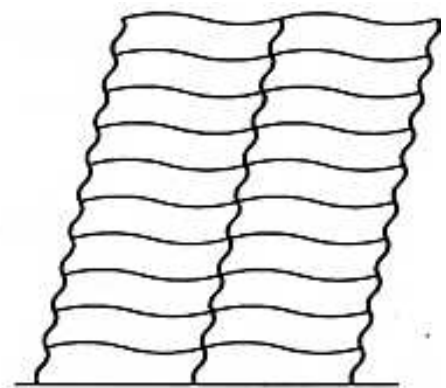

c

Fig. 4: Different kinds of deformations of bending frames induced by earthquake force: a) bending frame, b) deformation of chord thrust, c) deformation of shear moment.

Generally, using of concrete and steel in structures always has been in attention. In recent decades, a new structural system has used in structures which combines steel and concrete in a new way. In this system the beams are steel and columns are reinforced concrete. Use of steel beam instead of concrete beam in the reinforced concrete frames with big span solved the problem of high depth and large space occupied by the concrete beams. In most cases in steel frames with big span the section of beam is bigger than that of column, which makes it difficult to get the measure of strong column-weak beam. This issue causes unsuitable nonlinear behavior of structure under the seismic loads which can be decreased by replacement of steel beam instead of concrete column in RCS bending frames. 


\section{Connection of steel beam to concrete column (RCS)}

Advantages of both kinds of steel and concrete structure can be utilized in the composite structure. It means that structures surrounded with concrete have more flexibility than the concrete structures and at the same time are harder and are less tend toward buckling in compare to the steel structures. The composite members are more resistant to fire than the steel ones, have less weight and dimensions compared to the members of reinforced concrete members, and are more expensive than the concrete structures with administration more difficult than the steel structures. Another advantage of this system is administration of rigid connection [9].

In the RCS system which includes steel beam and reinforced concrete columns, for an easy administration of connections and flexibility of system, a weak steel section is placed in the column core. One of advantage of the system is proper flexibility and use of continuous beam and in the case of need to beam splice the joint point can be transferred to the position in which moment is equal to zero [10].

The most important part of the RCS bending frame is connection of the steel beam to the concrete column. Connections in these frames are divided into the two general groups of connection with bracing beam and connection with bracing column from the joint area. In connection with bracing beam from the joint area, the steel beam totally passes through the concrete connection orifice (Fig. $5 a)$. In the position in which two beams pass the joint area, one of bracing beams is discontinuous which is connected to the continuous beam using shear connection and the reinforced sheets are used for creating the bending continuity. In the created connection by method of bracing column from the joint area, the concrete column passes totally from the joint area and the steel beam is connected to the concrete column through the cover plate and connecting devices (Fig 5b).

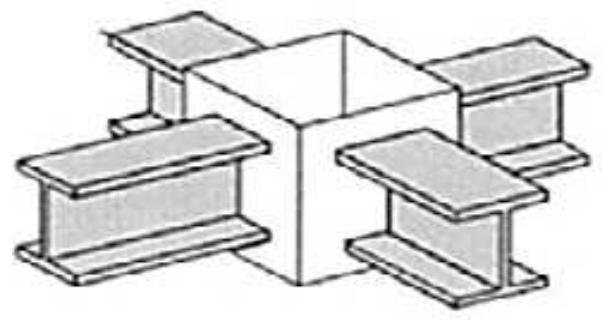

b

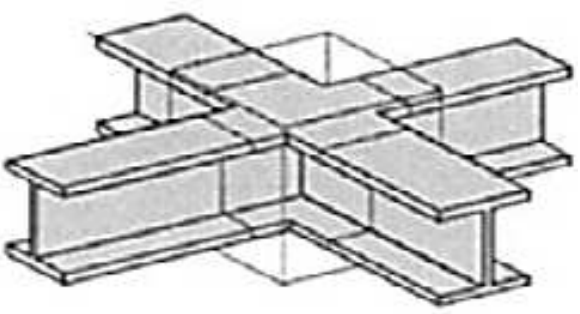

Fig. 5: a) RCS connection with bracing beam from the joint area b) RCS connection with bracing column from the joint area.

Studies about RCS connections have been focused more on the connection with bracing beam [11] and fewer studies have been performed on the connections with bracing column.

\section{Research method}

The method of this study was analysis of finite element using ABAQUS software and data were analyzed by EXCEL. In this study also we used 8-node element of normal 3dstress which numerical integration of this element is performed by Gauss method. In this software we can use arch - length (Rix) and Newton-Raphson methods which in this study we used the arch-length method.

\subsection{Concrete modeling}

For concrete modeling using ABAQUS software, there are three different qualities in the predefined materials of this software which in this study we used the behavior model of concrete damage plasticity. The main used parameters in this study included: viscosity, concrete uniaxial compressive and tensional stress-strain diagrams. For other parameters of this model we consider the suggested values by the software. Solution of the finite element based on theory of elasticity has high potential of early divergence. We can mention a lot of reasons for this problem which the most important one is decreasing the sever hardness after cracking in elements and high gradient changes in the cross section of yield surface. For solution of this problem, concrete is considered as a viscoelastic material. Considering viscosity parameter causes decrease of sensitivity in relation to the yielding surface and as the result convergence problems are solved to some extent. It is obvious that this value should be 
small to some extent that its effects on total response of structure can be ignored. In this study we use viscosity value of $0 / 00002$ to reach convergence.

As mentioned we need a geometric model of the steel bending frame with web angle for the first step of this study which this work has been done in the Part modal of advanced software of ABAQUS. These models were produced with capabilities of ABAQUS software in creating complex models. After creating of cross-section area of beam and column, use of some commands such as extrude and cut extrude and other useful capabilities in the ABAQUS software has been utilized for creating of geometric models. The geometric model of structures is used in order to produce the elements and creating finite element model after transferring to mesh modal in the ABAQUS software. It is worth mentioning that after complete the geometric models in the ABAQUS software in property model, the specifications of materials related to the different elements of structures will be applied.

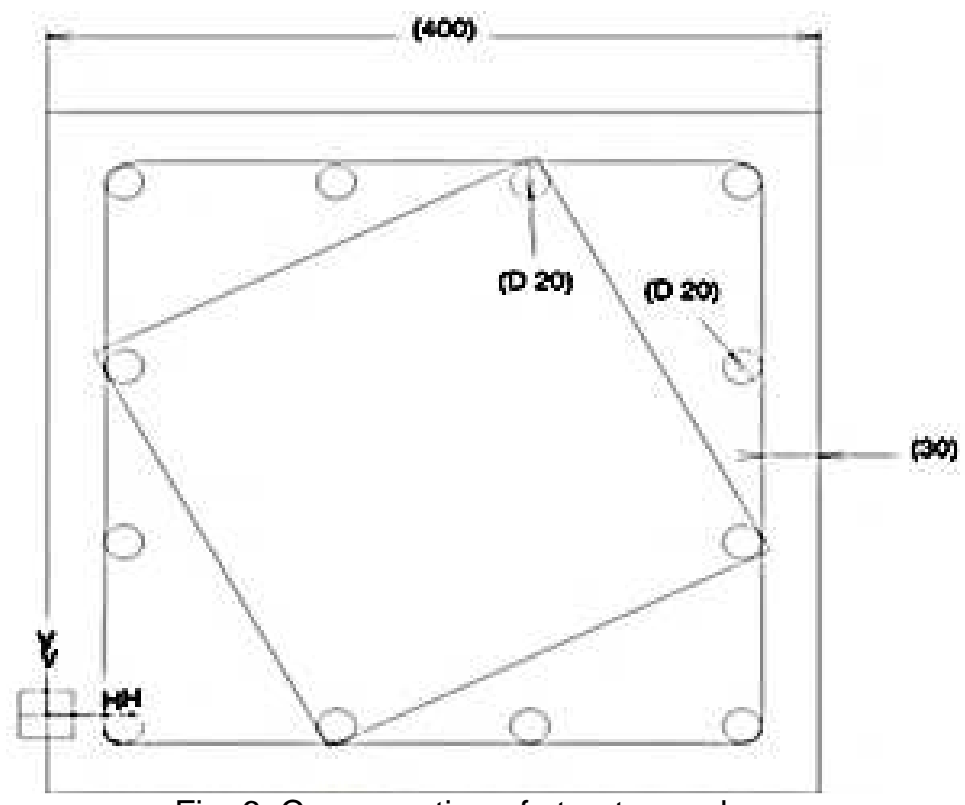

Fig. 6: Cross section of structure column.

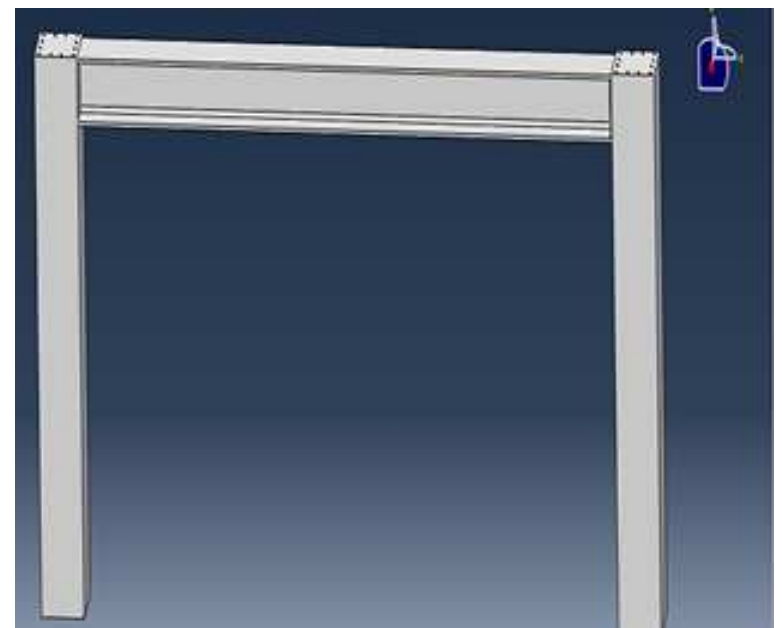

Fig. 7: 3D geometric model of CRS one - story frame. 


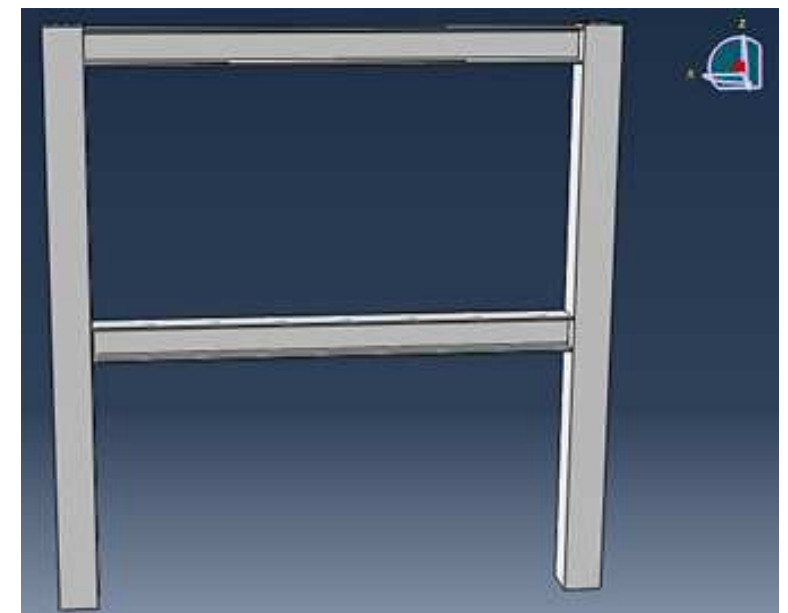

Fig. 8: 3D geometric model of CRS two - story frame.

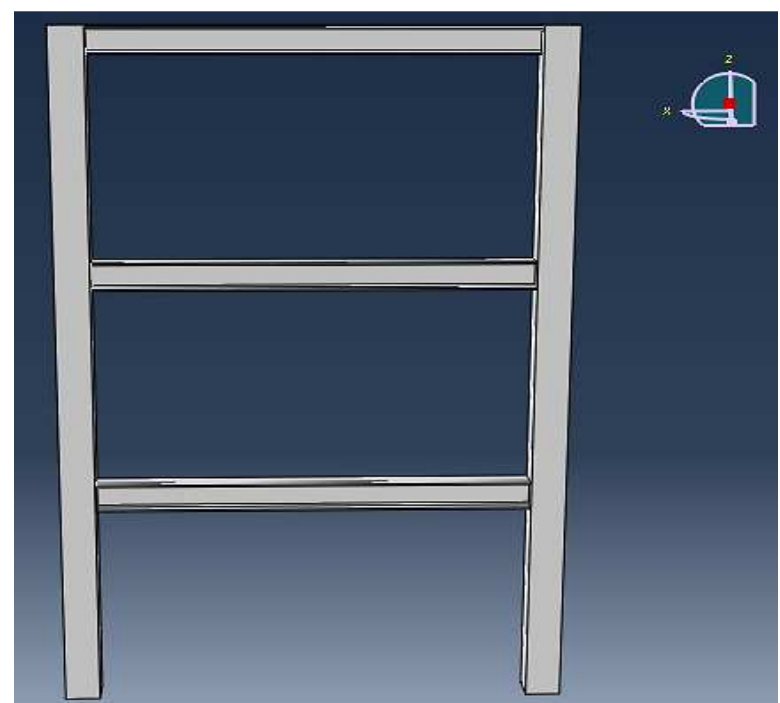

Fig. 9: 3D geometric model of CRS three - story frame.

For assembly each component can have either Dependent or Independent property. In Dependent, mesh can be performed on separated component while in Independent, mesh is performed on the assembled model. This study used the Dependent property for components. In the below figure, the final model of structures are shown in the ABAQUS software.

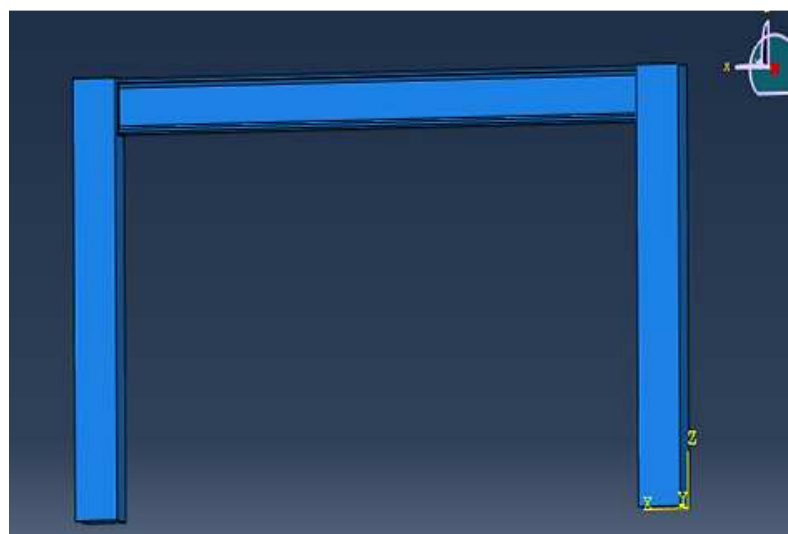

Fig. 10: Assembly of final model of CRS one - story frame. 


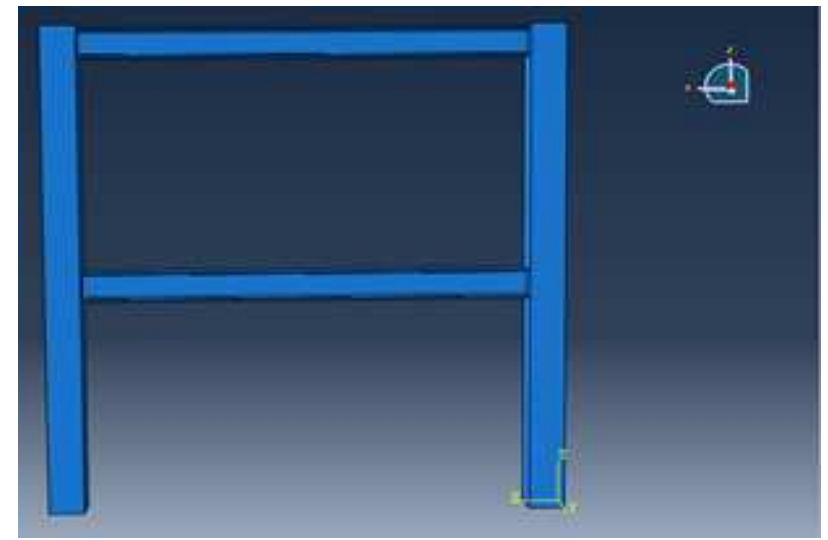

Fig. 11: Assembly of final model of CRS two - story frame.

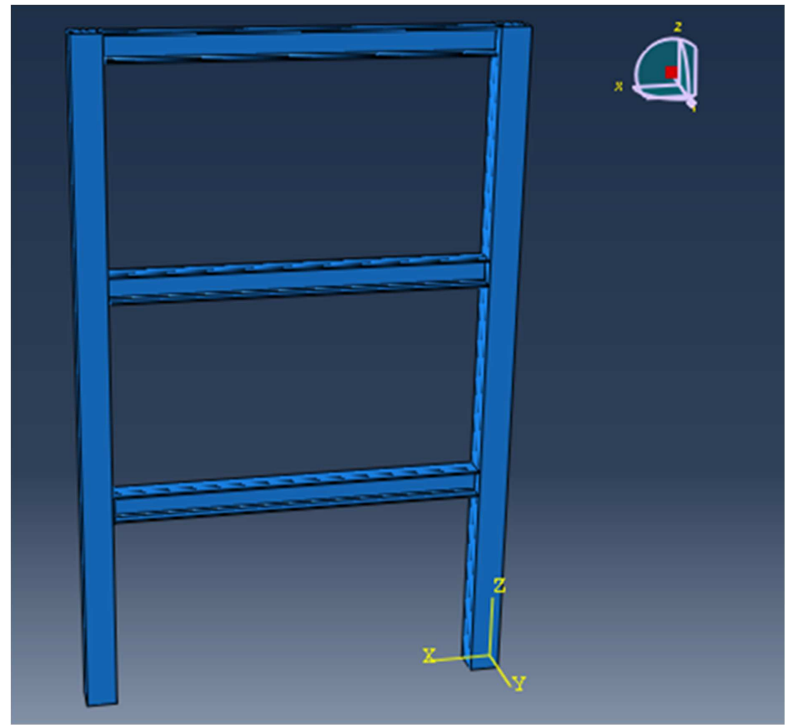

Fig. 12: Assembly of final model of CRS three - story frame.

According to the below figure, these specifications are applied to all steel components of the structure in the ABAQUS software.

Table 1: Specification of used materials.

\begin{tabular}{|c|c|c|c|}
\hline $\boldsymbol{\rho}\left(\frac{\mathbf{k g}}{\mathbf{m}^{3}}\right)$ & $\boldsymbol{v}$ (Poisson Ratio) & $\boldsymbol{E}\left(\frac{\mathbf{N}}{\mathbf{m}^{2}}\right)$ & material \\
\hline 7850 & 0.3 & $210 \mathrm{e} 9$ & steel \\
\hline & 0.2 & $25 \mathrm{e} 9$ & concrete \\
\hline
\end{tabular}

\subsection{Hysteresis analysis of structures}

After numerical analysis by the ABAQUS software, it is observed that with application of reciprocal loading to the structure, increase of lateral displacement led to increase of tension in the joint place which gradually reaches the yield point in some areas. In the below figure as another result the force-displacement curve (Hysteresis) is created based on the numerical analysis studies with the finite element method by ABAQUS software. The curve shows that increasing of ratio of lateral cycle displacement, the shear force bearable by structure will be increased. The trend of force changes displacement during first levels is linear which is induced by the initial effective hardness of structure. Hysteresis diagrams of the samples from the numerical analysis method have offered by the ABAQUS software. 


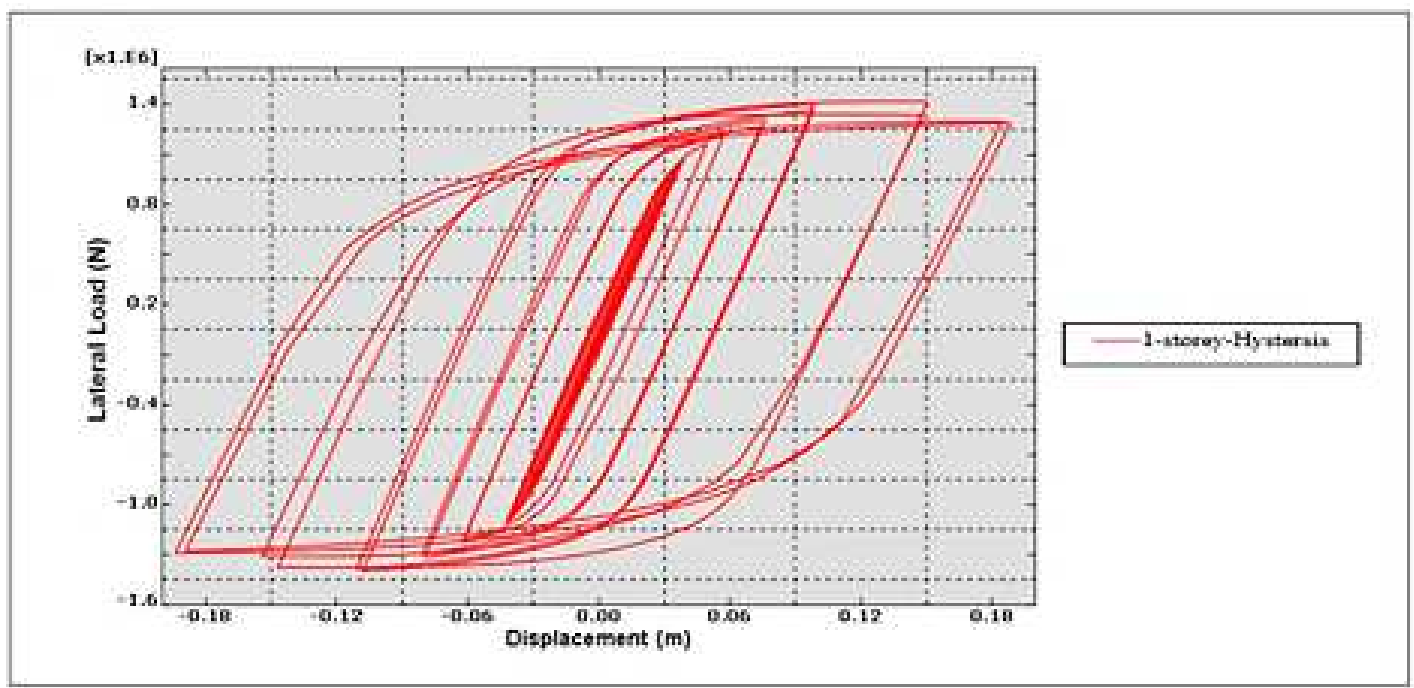

Fig. 13: Hysteresis curve of CRS one - story structure.

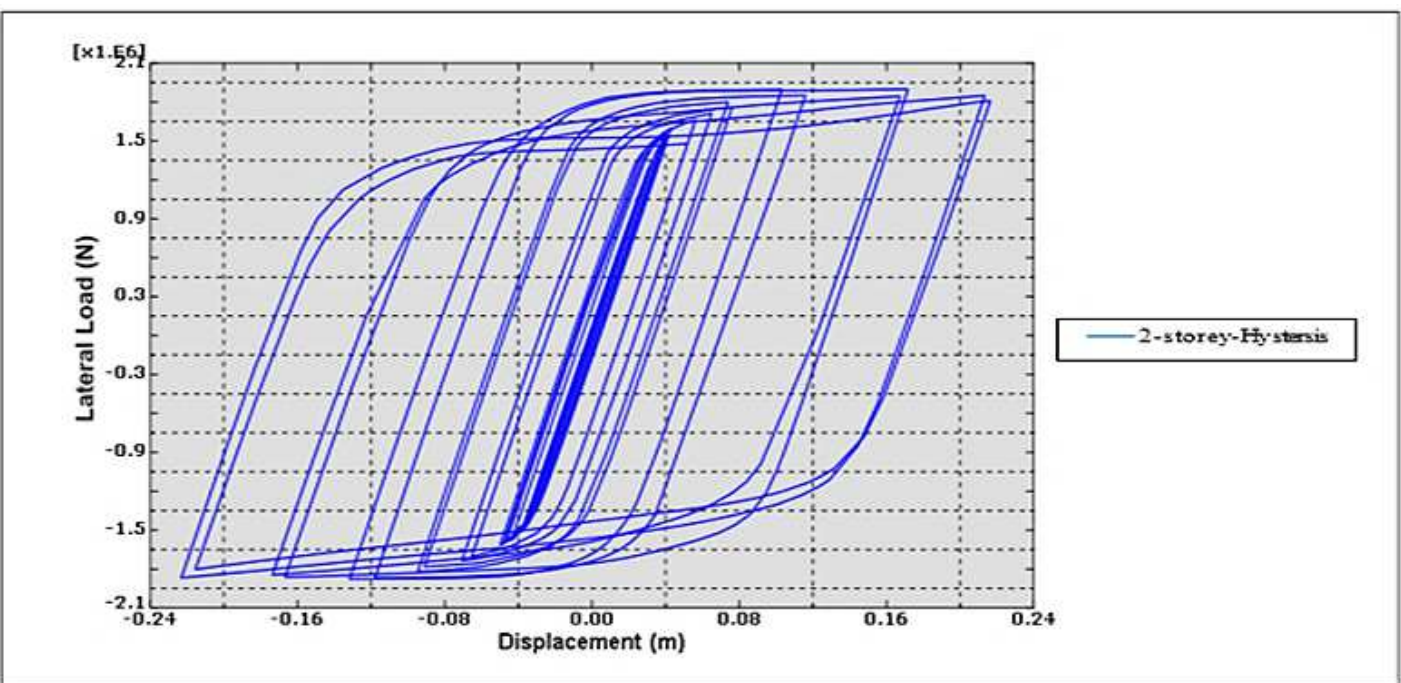

Fig. 14: Hysteresis curve of CRS two - story structure.

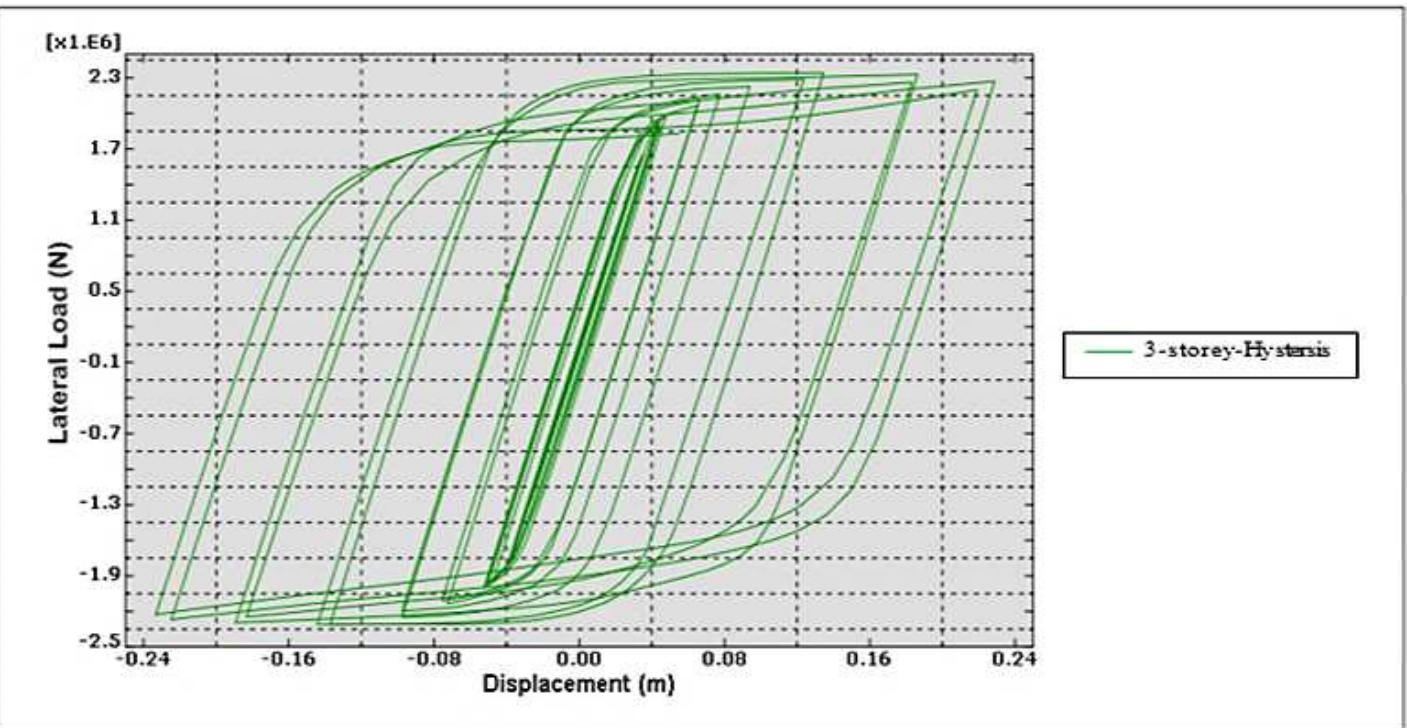

Fig. 15: Hysteresis curve of CRS three - story structure. 
In the Fig. 16, the hysteresis curves of the three under studied structures are shown. According to the below figure, with increase of stories of a building, the hysteresis curve became wider which is indicative of more energy absorption compared to the one-story and two-story structures. It also has more flexibility, lateral resistance and final displacement compared to other samples.

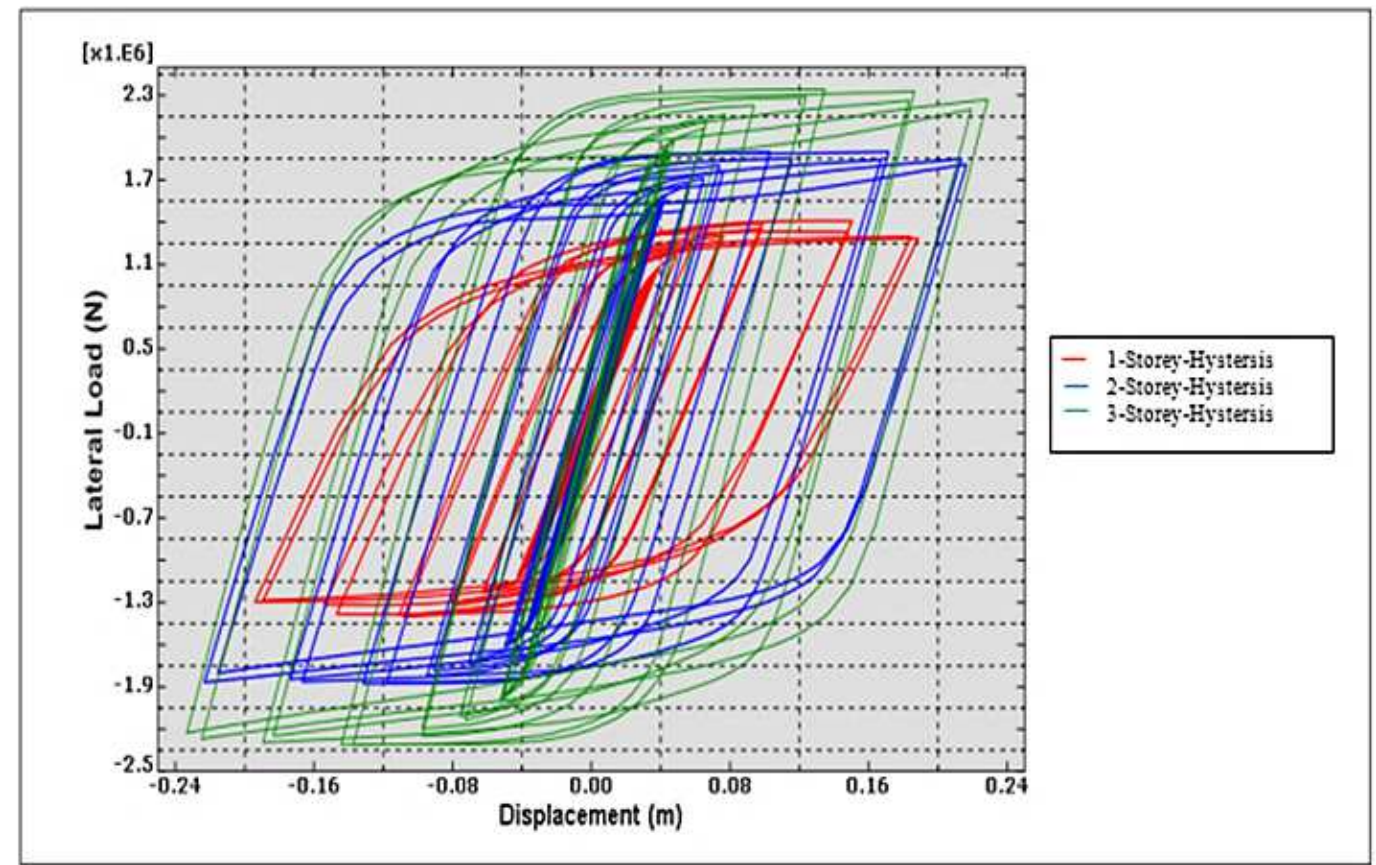

Fig. 16: Hysteresis curves 1, 2, 3 storey.

In Table 2, the seismic parameters resulted from analysis of hysteresis diagrams of under studied models have been offered in this study. Ratio of capacity of yield of one-story structure to the predicted yield capacity is about $71 \%$ of $F_{y} / F_{y p}$, while this ratio for the two- and three- story structure is $74 \%$ and $75 \%$ respectively.

From the Table 2 and hysteresis diagrams it is obvious that with increase of number of stories, in addition to the increase of flexibility of structure, area under the hysteresis curve which is indicative of value of dissipated energy, also have growing trend, in such a way that capacity of energy absorption in the three-story structure compared to the two- and one-story ones has increased $37 \%$ and $18 \%$ respectively.

Table 2: summary of results of under studied samples under cyclic loading.

\begin{tabular}{|c|c|c|c|c|c|}
\hline Model & $\begin{array}{c}\boldsymbol{F}_{\boldsymbol{y}} \\
\mathbf{k N}\end{array}$ & $\begin{array}{c}\boldsymbol{F}_{\boldsymbol{y p}} \\
\mathbf{k N}\end{array}$ & $\begin{array}{c}\boldsymbol{K}_{\boldsymbol{e}} \\
\mathbf{k N} / \mathbf{m m}\end{array}$ & $\begin{array}{c}\boldsymbol{\Delta}_{\mathbf{0 . 8}} \\
\mathbf{m m}\end{array}$ & $\begin{array}{c}\text { Energy } \\
\mathbf{k N m m}\end{array}$ \\
\hline CRS-1 Story & $1006 / 88$ & $14123 / 51$ & $5 / 39$ & $179 / 28$ & $443416 / 63$ \\
\hline CRS-2 Story & $1438 / 25$ & $1926 / 92$ & $6 / 97$ & $214 / 97$ & $572611 / 95$ \\
\hline CRS-3 Story & $1718 / 38$ & $2302 / 05$ & $7 / 74$ & $231 / 98$ & $699595 / 29$ \\
\hline
\end{tabular}

On the other hand, elasticity hardness of three-story web angle increase $31 \%$ and $10 \%$ compared to the two- and one- story structure respectively.

One of measurable parameters of for evaluation of vulnerability of structures is maximum lateral displacement. Generally, limitation of relative displacement of stories is dependent upon some factors such as high seismic zone, number of stories of structure and importance of structure.

Fig. 17 shows the maximum relative displacement of one- , two- and three- stories structure. In all the cases, values of lateral displacement satisfy the determined values in the regulation. 


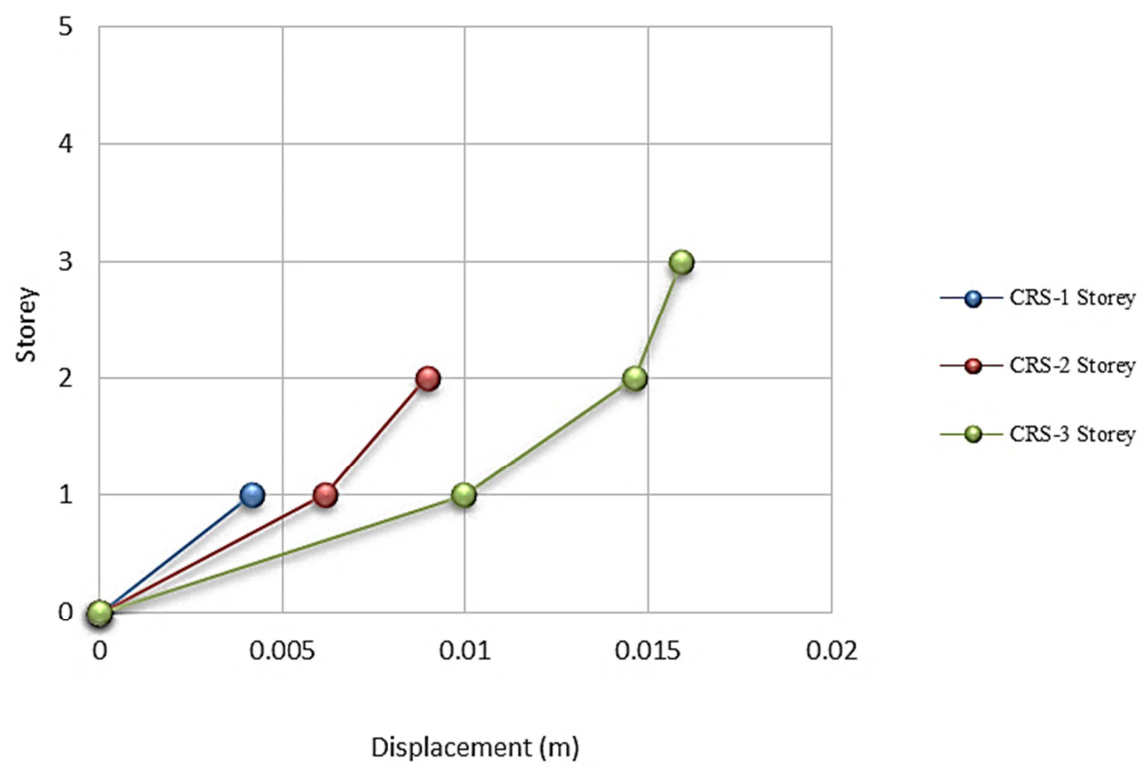

Fig. 17: Maximum relative displacement of one - , two - and three - stories structure.

Fig. 18 shows diagram of shear force of the under studied structures. It indicate that with increase of number of stories, shear force also will get increase, and value of shear force of two- story structure increases $27 \%$ compared to the one- story structure and this value in three-story structure increases $39 \%$ and $16 \%$ compared to the one- and two-story structures respectively.

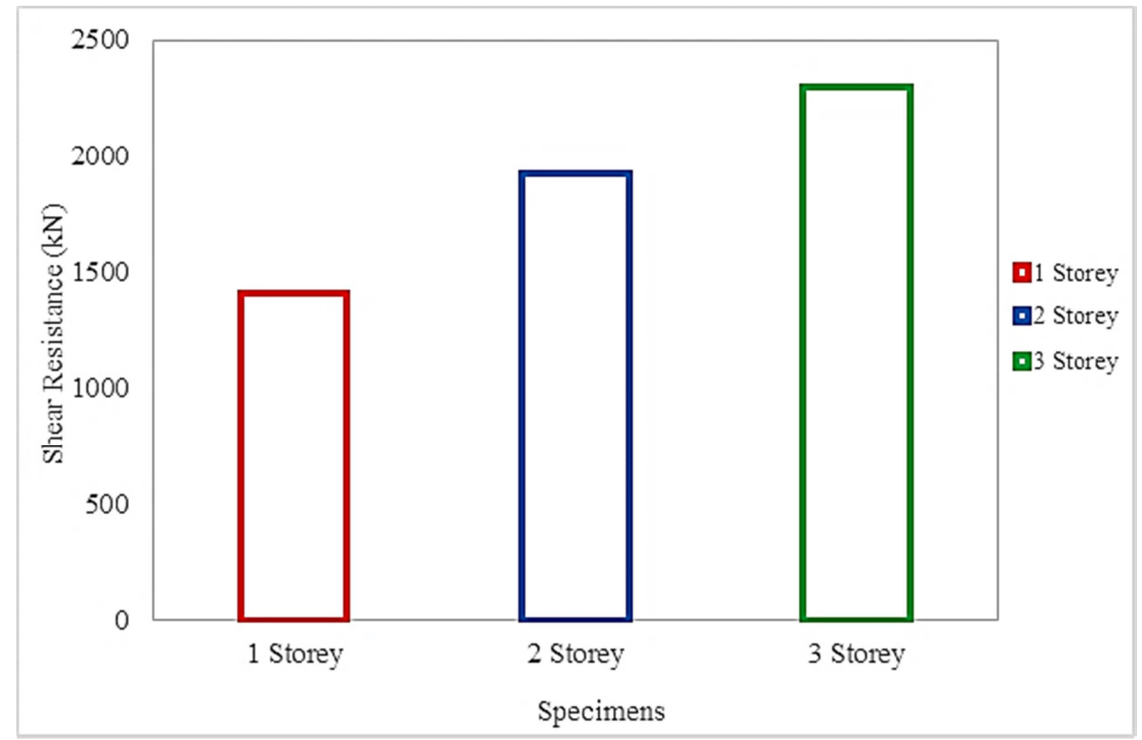

Fig. 18: Shear force of the under studied structures.

\section{Conclusion}

Generally, imposed force on structures due to the sever earthquake is very larger than the value laid down in the earthquake regulations. Even in some cases these forces are several times of the value obtained from the calculation of earthquake force based on the regulations. Modern technology in construction requires comprehensive efforts of private and governmental institutions to provide grounds for acceptance of this technology in society. Use of modern technology and observing of necessary technical and scientific methods based on international regulations lead to desirable construction, speed in production and capital return. In the RCS system which is included of steel beam and reinforced concrete column, we use weak steel profile in the column core. Another advantage of this system is flexibility and use of continuous beam. In the case of need of beam splice we can transfer the joint point to a region in which moment is equal to zero. According to the data we can conclude that: 
Increasing of stories of a construction, hysteresis curve become wider which is indicative of more energy absorption compared to the one- and two-story structures. It also shows more flexibility, lateral strength and final displacement compared to other under studied cases. Increasing the number of stories, in addition to increase of structure flexibility, lead to the growth of the under the hysteresis curve area in such a way that energy absorption capacity in the three- story structure has $37 \%$ and $18 \%$ increase compared to the two- and one- story structure respectively. The most important presumable cases include controlling results obtained from computation and obtaining values of maximum lateral displacement of stories. One of measurable parameters for evaluation of vulnerability of structures is the maximum lateral displacement of structures. This parameter has been one of controlling factor of earthquake damage in the regulations. Generally, limitation of relative displacement of stories is dependent upon some factors like high seismic zone, number of stories of a structure, and importance of a structure.

\section{Recommendations} damages,

- Execution of designs and new ideas in the areas prone to earthquake in order to decrease the

- Use of this method for increasing of quality and shortening of path,

- Investigation about result of this method compared to other offered methods,

- Study about use of other methods about this problem and comparison between the obtained results with that of this study.

\section{References}

[1] Deputy Planning and strategic supervision of president, Regulations about Design and Execution of Cold-Rolled Structures, publication No. 12, 2012.

[2] ESMAEILINIARI, SH. - ASGHARINIARI, A.: Evaluation of Seismic Behavior of Steel Bending Frame Using Different Methods of Seismic Analysis. The fifth national congress on civil engineering, Ferdowsi University of Mashhad, Iran, 2010.

[3] GHOJI, R. - KARAMI, M.: Evaluation about Flexibility of Bending Steel Frames with Resistance against Earthquake by Use of ADAS Yielding Dampers. The fourth national conferences about strengthening and maintenance of sustainable building, 2011.

[4] HOSSEINIHASHEMI, B. - PARVARI, A.: Comparison between Performance of Structure with Special Bending Frame and Steel Normal Bending Frame Designed with Standard 3rd Version of 2899. The 5th National Congress on Civil Engineering, 2010, pp.14-16.

[5] MADNDUST, R.: Evaluation about Mechanical Properties of Concrete with High Resistance, Reinforced Concrete. Steel Structures and Concrete Technology, the 6th International Conference on Civil Engineering, 2003.

[6] MOSTAFAVINEJAD, D. - FAZILATI, M.: Loading and Load-Bearing Systems. Ardakan press, Esfahan, 2001.

[7] ROFOOEI, F. R. - MONAJEMI-NEZHAD, S.: Decentralized control of tall buildings. The structural design of Tall and Special Buildings, Vol. 15 (2), 2006, pp. 153-170.

[8] SHEIKH, T. M. - DEIERLEIN, G. G. - YURA, J. A. - JIRSA, J. O.: Beam-column moment connections for composite frames, Part 1. Journal of Structural Engineering, Vol. 115 (11), 1989, pp. 2858-2876.

[9] TAHUNI, Sh.: Design of Steel Structure based on Iran Steel Regulation. Elmadab press, 1st edition, No. 18, 2010.

[10] VASEGHIAMIRI, J. - ESMAEILTABAR, N. P. - JALALI, G. H.: Investigation about Frictional Damper on the Seismic Behavior of Chevron Steel Frame. The 9th National Congress on Civil Engineering, Isfahan University of Technology, 2012.

[11] SAEEDEH, G. - KHEYRODDIN, A. - NAZERYAN, M. - MIRTAHERI, S. M. - GHOLHAKI, M.: Nonlinear behavior of connections in RCS frames with bracing and steel plate shear wall. Steel and Composite Structures, Vol. 22, No. 4, 2016, pp. 915-935. 